\title{
Influence of bread volume on glycaemic response and satiety
}

\author{
Pat Burton* and Helen J. Lightowler \\ Nutrition and Food Science Group, School of Biological and Molecular Sciences, Oxford Brookes University, \\ Gipsy Lane Campus, Headington, Oxford OX3 OBP, UK
}

(Received 13 January 2006 - Revised 6 June 2006 - Accepted 6 June 2006)

\begin{abstract}
The role of carbohydrates in health and disease has received a high profile in recent years, in particular the glycaemic index (GI) as a physiological classification of carbohydrate foods. A common carbohydrate source in the UK is white bread, which is considered to have a high GI value and low satiety value. In the present study, the possibility of favourably altering the GI of white bread by manipulating bread structure (loaf form) was investigated. In a randomised repeated-measures design, ten subjects were tested for glycaemic and satiety responses to four loaves of varying volume, but of consistent macronutrient content. Peak plasma glucose levels and GI values were shown to be significantly reduced by lowering loaf volume $(P=0.007, P<0.001$ respectively). In addition, a greater satiety index (SI) was seen with decreased loaf volume $(P<0 \cdot 001)$. In conclusion, the present study demonstrates that reducing the volume of white bread, which is generally considered to be high-GI and lowSI, can favourably alter metabolic and appetite responses. Relatively small differences in the GI of regularly consumed starch foods have been shown to have beneficial effects on health.
\end{abstract}

Glycaemic index: Satiety: Loaf volume: Gastric emptying rate

In recent years, there has been considerable discussion regarding the effect of modifying dietary carbohydrate on blood lipid profiles, the metabolic syndrome, insulin resistance and risk of type 2 diabetes (Astrup \& Raben, 1995; Ebbeling et al. 2003). Differences in postprandial glucose response to various carbohydratecontaining foods have been demonstrated in healthy and diabetic subjects (Jenkins et al. 1981). The glycaemic index (GI) is a physiological classification widely accepted for carbohydrate foods, with implications in health and disease. The GI is defined as the incremental area under the blood glucose curve (IAUC) of a $50 \mathrm{~g}$ available carbohydrate portion of a test food expressed as a percentage of the response to $50 \mathrm{~g}$ available carbohydrate of a standard (reference) food taken by the same subject, on a different day (Food and Agriculture Organization \& World Health Organization, 1998). The principle is that the slower the rate of carbohydrate absorption, the lower the rise of blood glucose level and the lower the GI value (Brand et al. 1991). Indeed, high-GI foods are characterised by fast-release carbohydrate and higher blood glucose levels. A GI value $\geq 70$ is considered high, a GI value 56-69 inclusive is medium and a GI value $\leq 55$ is low, where glucose $=100$ (Brand-Miller et al. 2003a).

A number of factors have been shown to influence the glycaemic response to carbohydrate foods including food form and particle size (Granfeldt et al. 1991), the structure of the starch component (Noakes et al. 1996), degree of starch damage through food processing (Jenkins et al. 1986), the inclusion of whole kernels (Hallfrisch \& Behall, 2000), viscous fibres (Alvarado et al. 1999) and resistant starch
(RS; Langkilde et al. 2002). Mechanisms of reduction in glycaemic response appear to be changes in gastric emptying rate and/or starch amylolysis, involving starch gelatinisation and retrogradation.

The compactness of food influences starch digestion, demonstrated in studies on glycaemic response to pasta compared with white wheat bread (Hoebler et al. 1999). In studies of bread dough, light microscopy, scanning and electron microscopy show adhesion of neighbouring networks of protein in flour particles in the transformation of water and flour into viscoelastic dough, where the gluten protein fills the space between the starch granules (Amend \& Belitz, 1991). Of equal importance is the extent of the physical barrier created by the protein network, influencing the relative accessibility of starch to amylase (Hoebler et al. 1999; Hayta \& Alpaslan, 2001).

Of the starch foods in the UK, bread forms probably the most basic staple. The UK bread and morning-goods market, one of the largest sectors in the food industry, produces almost twelve million loaves and packs per $\mathrm{d}$ (Federation of Bakers, 2005). Moreover, white bread sales constitute more than $70 \%$ of sales in the UK. The result of long-term development in the bread-making process is a highly favoured white bread, of relatively high GI and of low satiety value (Wolever et al. 1994; Foster-Powell et al. 2002).

Relatively small differences in the GI of regularly consumed starch foods have shown beneficial effects on health, including reduced CVD risk and glycaemic control (Frost

Abbreviations: AUC, incremental area under the response curve; GI, glycaemic index; IAUC, incremental area under the blood glucose curve; RS, resistant starch; SI, satiety index.

*Corresponding author: Mrs Pat Burton, fax +44 1865 483242, email Patmargburton@brookes.ac.uk 
et al. 1998; Liu et al. 2000; Wolever \& Mehling, 2002; Brand-Miller et al. 2003b). Thus, investigations into ways of reducing the GI and increasing the satiety index (SI) of white bread are of important application. In light of the above, the aim of the present study was to investigate the relationship between food structure and composition and glycaemic response and satiety of white bread.

\section{Methods}

\section{Subjects}

Ten healthy subjects (four male and six female; age $50 \cdot 4$ (SD 9.1) years; BMI $23.9(\mathrm{SD} 2.0) \mathrm{kg} / \mathrm{m}^{2}$ ) were recruited to the study. Interested subjects were asked to complete a healthscreening questionnaire to check against ill health, including clinically abnormal glucose metabolism (fasting blood glucose $>6.0 \mathrm{mmol} / \mathrm{l}$ ) and any medical conditions or medications that might affect glucose regulation, gastric emptying, body weight, appetite or energy expenditure. Mean fasting plasma glucose level was $5 \cdot 3(\mathrm{SD} 0 \cdot 1) \mathrm{mmol} / \mathrm{l}$.

Anthropometric measurements were made in the fasting state, using standardised methods, on the morning of the first test. Height was recorded to the nearest centimetre using a stadiometer (Seca Ltd, Birmingham, UK), with subjects standing erect and without shoes. Body weight was recorded to the nearest $0 \cdot 1 \mathrm{~kg}$ using the Tanita BC-418 MA (Tanita UK Ltd, Yiewsley, Middlesex, UK), with subjects wearing light clothing and no shoes. BMI was calculated using the standard formula: weight $(\mathrm{kg}) /$ height $(\mathrm{m})^{2}$.

Ethical approval was obtained from the University Research and Ethics Committee at Oxford Brookes University (Oxford, UK). Subjects were given full details of the study protocol and the opportunity to ask questions. All subjects gave written informed consent before participation.

\section{Test breads}

White bread loaves were made from $500 \mathrm{~g}$ white wheat flour (Carr's white strong bread flour), $8 \mathrm{~g} \mathrm{NaCl}, 6 \mathrm{~g}$ sugar, $287 \mathrm{ml}$ water, $6 \mathrm{~g}$ butter, $7 \mathrm{~g}$ skimmed milk powder and $8 \mathrm{~g}$ dehydrated yeast without additives (Fermipan ${ }^{\circledR}$; DSM Bakery Ingredients, Dordrecht, The Netherlands).

Bread loaves of different volumes were prepared using a standard, readily available home bread-making machine (Breadman Pro; Russell Hobbs, Manchester, UK). Using the dough-cycle function to ensure consistency of mixing and kneading intensities, while making possible manual manipulation of proving times, different bread volumes were produced of identical macronutrient content, including both water and yeast. Proving and baking conditions for each test bread are shown in Table 1. Dough was proved once (rise 1), shaped, reproved (rise 2) and then baked in a conventional oven $\left(200^{\circ} \mathrm{C}\right)$ for $20 \mathrm{~min}$. Rises 1 and 2 took part as part of the bread-making machine cycle. For the highest volume loaf, the dough was removed from the bread maker at the end of the cycle, punched back and left to rise for one final proving, at room temperature (Table 1).

Following baking, the temperature at the centre of each loaf was determined using a kitchen food thermometer (Kitchen Craft Ltd, Weymouth, Dorset, UK). In addition, the weight of each loaf was measured at 5 min intervals for approximately $1 \mathrm{~h}$, until complete cooling, as a crude assessment of water loss and movement through the loaf matrix. Volume measurement was carried out by seed displacement methodology, using a volume-weight calibration (Table 1).

\section{Study protocol}

The method used to measure glycaemic response and to calculate the GI value was in line with procedures recommended by the Food and Agriculture Organization \& World Health Organization (1998). In addition, on the day preceding a test, subjects were asked to restrict their intake of alcohol and caffeine-containing drinks and to refrain from intense physical activity (for example, long periods at the gym, excessive swimming, running, aerobics). To minimise the possible influence of the second-meal effect, subjects were asked to refrain from eating an extra-large evening meal or have an unusually high food intake the day preceding a test (Wolever, 1990; Granfeldt et al. 2006). Where possible, subjects ate a similar meal type on the evening before testing. All foods were tested in subjects after a $12 \mathrm{~h}$ overnight fast.

Four bread loaves with different volumes (test breads) were administered to subjects in a randomised, repeated-measures design, with each subject acting as his/her own control. All test breads were compared with a standard food (glucose) and were tested in equivalent amounts $(50 \mathrm{~g})$ of available carbohydrate. As blood glucose responses vary within subjects from day to day, the standard food was tested three times in each subject. Thus, subjects tested each test bread once and the standard food three times in random order on separate days, with at least a $1 \mathrm{~d}$ gap between measurements to minimise carry-over effects. All test breads and the standard

Table 1. Proving and baking conditions of test breads*

\begin{tabular}{|c|c|c|c|c|c|c|c|c|c|c|}
\hline & \multirow[b]{2}{*}{ Rise 1 (min) } & \multirow[b]{2}{*}{$\mathrm{Pb}+(\mathrm{s})$} & \multirow[b]{2}{*}{ Rise 2 (min) } & \multirow[b]{2}{*}{$\mathrm{Pb}+(\mathrm{s})$} & \multirow[b]{2}{*}{ Rise 3 (min) } & \multicolumn{2}{|c|}{ Volume (ml) } & \multirow[b]{2}{*}{ Temperature $\left({ }^{\circ} \mathrm{C}\right)$} & \multicolumn{2}{|c|}{$\begin{array}{l}\text { Weight }(g) \text { after } \\
\text { cooking }\end{array}$} \\
\hline & & & & & & Mean & SD & & $0 \mathrm{~min}$ & $50 \mathrm{~min}$ \\
\hline Bread 1 & 10 & 10 & 2 & - & - & 1100 & 100 & 140 & 793 & 784 \\
\hline Bread 2 & 30 & 10 & 12 & - & - & 1700 & 150 & 160 & 780 & 767 \\
\hline Bread 3 & 60 & 10 & 30 & - & - & 2400 & 150 & 170 & 773 & 758 \\
\hline Bread 4 & 40 & 10 & 25 & 10 & 50 & 3000 & 150 & 190 & 760 & 744 \\
\hline
\end{tabular}

$\mathrm{Pb}$, punchback time.

* Rises 1 and 2 in bread-making machine cycle; rise 3 outside machine, following third 'punchback'.

† Manual punching down of risen dough. 
food were served with $200 \mathrm{ml}$ water. A further $200 \mathrm{ml}$ water was given during the subsequent $2 \mathrm{~h}$. Subjects were asked to eat the test breakfast within a $10-12$ min period to reduce the influence of chewing on particle size (Hoebler et al. 1998).

\section{Blood glucose measurements}

Finger-prick blood samples were taken for capillary blood glucose analysis. Recent reports suggest that capillary blood sampling is preferred for reliable GI testing (Food and Agriculture Organization \& World Health Organization, 1998; Wolever \& Mehling, 2003). A fasting blood sample was taken at 0 min and the standard food or test bread was consumed immediately after this. Further blood samples were taken at 15, 30, 45, 60, 90 and 120 min after starting to eat.

Blood was obtained by finger-prick using the Glucolet 2 multi-patient lancing system (Bayer HealthCare, Leverkusen, Germany). Before a finger-prick, subjects were encouraged to warm their hand to increase blood flow. Fingers were not squeezed to extract blood from the fingertip as this may dilute with plasma. Blood glucose was measured using Ascensia Contour ${ }^{\circledR}$ automatic blood glucose meters (Bayer HealthCare). The blood glucose meters were calibrated daily using control solutions from the manufacturer and were also regularly calibrated against a clinical dry chemistry analyser (Reflotron ${ }^{\circledR}$ Plus; Roche Diagnostics Ltd, Lewes, East Sussex, UK) and the HemoCue Glucose $201+$ analyser (HemoCue ${ }^{\circledR}$ Ltd, Dronfield, Derbyshire, UK).

Fig. 1 shows the Pearson regression and Bland-Altman analyses (Bland \& Altman, 1986) for a random selection of 106 blood samples simultaneously measured using the
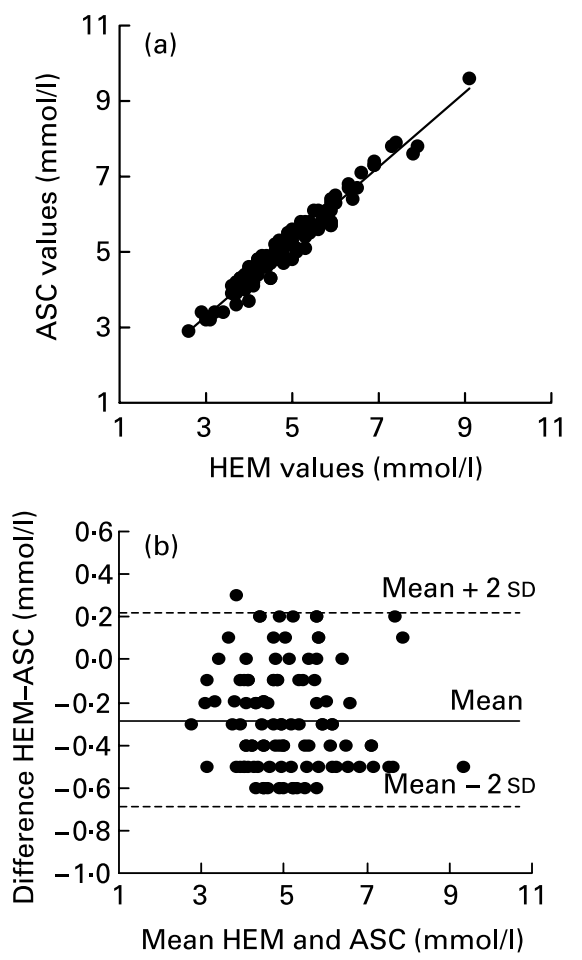

Fig. 1. Pearson regression (a) $\left(y=0.9912 x+0.3143 ; R^{2} 0.9562\right)$ and Bland-Altman analyses (b) of blood glucose measurements between the Ascensia Contour (ASC) and HemoCue $201+$ analyser (HEM).
Ascensia Contour ${ }^{\circledR}$ and the HemoCue Glucose $201+$ analyser. There was a very strong correlation $(r \quad 0.978 ; P<0.001)$ and good agreement (mean difference -0.3 (95\% CI -0.3 , $-0.2) \mathrm{mmol}$; limits of agreement -0.75 and 0.21 ) between blood glucose measurements using the automatic analyser and the HemoCue analyser.

\section{Calculation of glycaemic index}

The IAUC, ignoring the area beneath the baseline, was calculated geometrically for each test bread (Food and Agriculture Organization \& World Health Organization, 1998). The IAUC for each test bread eaten by each subject was expressed as a percentage of the mean IAUC for the reference food eaten by the same subject:

$$
\mathrm{GI}=(\text { IAUC test bread } / \text { IAUC reference food }) \times 100 \text {. }
$$

The GI of each test bread was taken as the mean for the whole group.

\section{Assessment of satiety}

At the same time as the finger-prick blood samples (i.e. 0, 15, $30,45,60,90$ and $120 \mathrm{~min}$ ), the subjective feeling of satiety was measured using an equilateral seven-point rating scale (Holt et al. 1995). The satiety response for each test bread was quantified as the incremental area under the response curve (AUC), ignoring area beneath the baseline. SI scores were obtained by dividing the satiety AUC for the test bread by the group mean satiety AUC for glucose and multiplying by 100 . Thus, glucose had an SI score of $100 \%$ and the SI scores of the test breads were expressed as a percentage of glucose.

Alertness ratings were included as a distraction from the importance of satiety ratings; in addition, all marks of ratings were covered manually immediately to prevent subjects referring to previous ratings (Holt et al. 2001).

\section{Statistical analysis}

Statistical analysis was performed using SPSS software (version 11.0.1; SPSS Inc., Chicago, IL, USA). Data are presented as means and standard deviations. To examine the correlation and agreement between the automatic analyser and the HemoCue Glucose 201 + analyser, Pearson's correlation coefficient and the method of Bland \& Altman (1986) were used. Repeated-measures ANOVA, with Bonferroni's correction, was used to compare glycaemic response and satiety rating between the four different bread loaf volumes. Statistical significance was set at $P<0.05$.

\section{Results}

Fig. 2 shows the mean IAUC for the test breads. Other parameters such as the fasting, peak rise, IAUC and GI values are presented in Table 2.

Peak rise in glucose was significantly different $(P<0 \cdot 001)$. Peak rise for bread 1 was significantly lower than corresponding values for breads 2,3 and $4(P=0 \cdot 19, P=0.002$ and $P=0 \cdot 001$, respectively). Bread 2 also produced a significantly lower peak rise glucose than bread $4(P=0.049)$. 


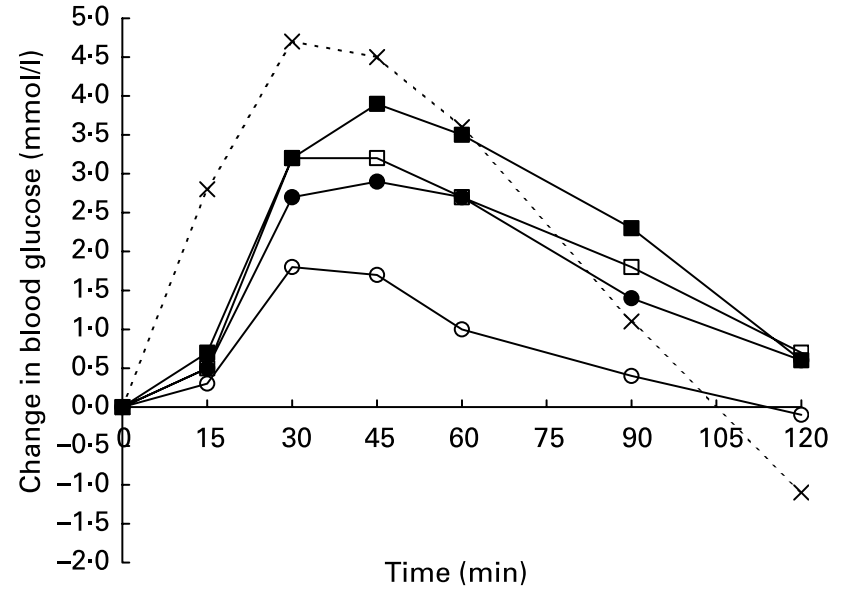

Fig. 2. Incremental area under the blood glucose curve for glucose and test breads: glucose $(\times)$; bread $1(\bigcirc)$; bread $2(\bullet)$; bread $3(\square)$; bread $4(\square)$.

There was a significant effect of bread volume on GI value $(P<0.001)$. The GI value for bread 1 was significantly lower than each of the higher volume breads: bread $2(P<0.001)$, bread $3(P=0.002)$ and bread $4(P<0.001)$. In addition, the GI values of breads 2 and 3 were significantly lower than for bread 4 ( $P=0.011$ and $P=0 \cdot 048$, respectively).

Satiety response for each of the test breads is shown in Fig. 3. SI values were 202 (SD 48), 235 (SD 51), 117 (SD 54) and 155 (SD 62) for breads 1, 2, 3 and 4, respectively. There was a significant effect of bread volume on satiety response $(P<0 \cdot 001)$. In particular, the SI of breads 1 and 2 was significantly higher than bread 3 ( $P=0.005$ and $P<0 \cdot 001$, respectively) and the SI of breads 2 and 3 was significantly higher than bread 4 $(P=0.035$ and $P=0.045$, respectively).

\section{Discussion}

The present study has shown that manipulation of bread dough proving time, resulting in lower loaf volume, can lead to reduced glycaemic response. Reducing bread volume from $3000 \mathrm{ml}$ to 2400,1700 and $1100 \mathrm{ml}$ led to 14,28 and $62 \%$ reductions in GI values, respectively. In addition, peak rise in glucose was significantly reduced by lower loaf volume, similar to the lente features of pasta (Granfeldt et al. 1991). The GI values of three of the breads (breads 2, 3 and 4) were above 70. This may be due to the use of a home-style bread maker, involving long proof times. The influence of manipulation of proof times was a salient feature of the present study.
Any condition or process leading to a breakdown or disruption of the starch granule will lead to more readily digestible starch, with a resultant higher blood glucose response (Granfeldt et al. 2000). This is due to a greater susceptibility of the granule to enzymic degradation by salivary and pancreatic amylases. Gelatinisation of the starch granule is an important concept in terms of enzyme access and bioavailability of glucose (Bornet et al. 1989; Rashmi \& Urooj, 2003). Importantly, any impact upon starch, which results in a limited swelling and gelatinisation, such as lowered bread loaf core temperature, and a denser bread matrix, as seen in the present study, will result in reduced postprandial glycaemic responses. Variation in starch-protein interactions in the loaves with differences in loaf temperature and matrix density may also play a part.

A reduced rate of starch hydrolysis due to greater starchprotein interactions is possible in the denser bread, where a lower loaf temperature may not allow breakdown of such interactions. Moreover, a slower rate of gastric emptying with denser, more compact bread cannot be ruled out. Granfeldt et al. (1991) showed an absence of any slower rate of amylolysis of thin linguine pasta using such methods, concluding that the reduced glycaemic response was more likely to be due to reduced gastric emptying rate.

All initial macronutrients in the original bread recipe were consistent; however, RS was not measured. It is possible that the reduced gelatinisation with reduced volume produced differences in RS. The substitution of digestible starch with RS may reduce the appearance of glucose in the blood and result in a lower GI value (Achour et al. 1997; Langkilde et al. 2002). Short-term consumption of RS has been demonstrated to enhance postprandial insulin sensitivity in healthy subjects (Robertson et al. 2003) and several ingredients with high levels of RS are becoming available commercially.

Interestingly, none of the breads in the present study produced mean plasma glucose levels below baseline fasting levels, often demonstrated in studies using white bread (Foster-Powell et al. 2002). This could be reflective of the nature of the milling of the flour used in the present study. The flour used is low-pressure-milled on air-floated rollers and is a more gentle milling action. Modern treatments of starch foods incorporate the generation of a number of forces upon the starch granule, such as shearing, compression and extreme heat treatment, facilitating more readily the important process of gelatinisation. The more gently milling action of the flour used in the present study may be a factor reducing damage to the starch granule. For the purpose of the present study, the bread recipe included Carr yeast also,

Table 2. Fasting plasma glucose and postprandial glucose characteristics (Mean values with their standard errors)

\begin{tabular}{|c|c|c|c|c|c|c|c|c|c|c|}
\hline & \multicolumn{2}{|c|}{ Glucose } & \multicolumn{2}{|c|}{ Bread 1} & \multicolumn{2}{|c|}{ Bread 2} & \multicolumn{2}{|c|}{ Bread 3} & \multicolumn{2}{|c|}{ Bread 4} \\
\hline & Mean & SEM & Mean & SEM & Mean & SEM & Mean & SEM & Mean & SEM \\
\hline Fasting glucose (mmol/l) & $5 \cdot 3$ & 0.1 & $5 \cdot 6$ & 0.2 & $5 \cdot 2$ & 0.1 & $5 \cdot 2$ & 0.1 & $5 \cdot 2$ & 0.2 \\
\hline Peak rise $(\mathrm{mmol} / \mathrm{l})$ & $5 \cdot 3$ & 0.4 & $2 \cdot 4^{\mathrm{a}}$ & 0.2 & $3 \cdot 4^{\mathrm{b}}$ & 0.5 & $3.9^{b}$ & 0.5 & $4 \cdot 4^{c}$ & 0.5 \\
\hline IAUC & 279 & 33 & 106 & 15 & 204 & 204 & 230 & 30 & 273 & 30 \\
\hline Gl value & - & - & $38^{\mathrm{a}}$ & 4 & $72^{b}$ & 72 & $86^{\mathrm{b}}$ & 9 & $100^{c}$ & 7 \\
\hline
\end{tabular}

IAUC, incremental area under the blood glucose curve; GI, glycaemic index.

${ }_{a, b, c}$ Mean values within a row with unlike superscript letters were significantly different $(P<0.05)$. 


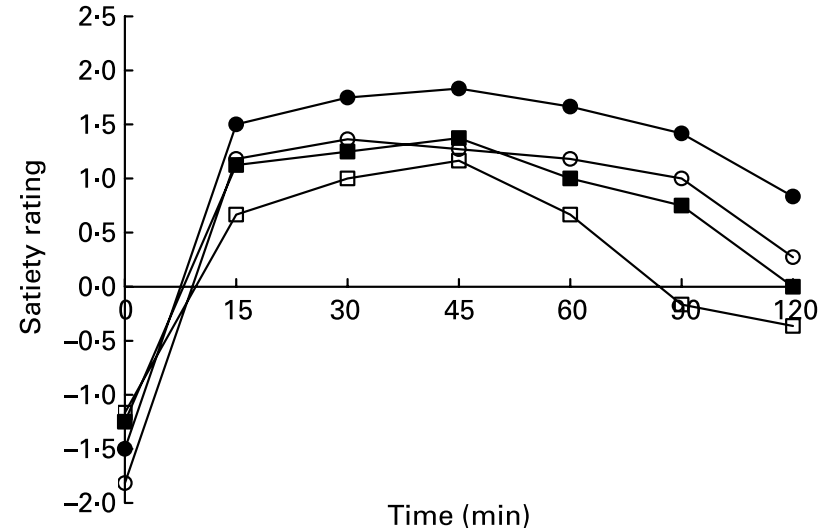

Fig. 3. Satiety response to test breads: bread $1(\bigcirc)$; bread $2(\bullet)$; bread 3 $(\square)$; bread 4 ( $\square$ ).

essentially without the action of vitamin $\mathrm{C}$ or amylases. This was used in order to more effectively reduce the volume of the bread with changes in rising times, otherwise overridden by the high-rising action of the yeast.

In the present study, an increase in satiety with decreased loaf volume was seen, although it was the second lowest volume (bread 2) that caused the greatest satiety response. The dense texture of bread 1 was disliked by many subjects, possibly influencing satiety scores. It is possible that differences in gastric fullness or extension, the presence of undigested or partially digested starch in the duodenum, jejunum or ileum, and postprandial glycaemia together determined satiety. A lower degree of gastric fullness with the higher volume bread is hypothesised to lead to a stronger urge to eat again following carbohydrate-rich meals containing such bread. Denser, coarse bread, for example, bread 2, may lead to increased satiety through a greater perceived fullness.

Automatic glucose meters are often used to measure glycaemic response due to their convenience. Velangi et al. (2005) found that glycaemic response determined by an automatic glucose meter (One Touch Ultra ${ }^{\circledR}$ ) was variable. However, the automatic glucose meters used in the present study (Ascensia Contour ${ }^{\circledR}$ ) showed a very strong correlation and good agreement with the HemoCue Glucose 201+ analyser.

The present study is the first to show a significant reduction in GI and significant increase in SI of white bread by reduction of bread volume to denser bread. Although the GI values of three of the four test breads remained high, i.e. $>70$, relatively small differences in the GI of regularly consumed starch foods have been shown to have beneficial effects on health, including reduced CVD risk and glycaemic control (Frost et al. 1998; Liu et al. 2000; Wolever \& Mehling, 2002; Brand-Miller et al. 2003b).

\section{Acknowledgements}

The present study was supported by a BBSRC studentship.

\section{References}

Achour L, Flourie B, Briet F, Franchisseur C, Bornet F, Champ M, Rambaud JC \& Messing B (1997) Metabolic effects of digestible and partially indigestible cornstarch: a study in the absorptive and postabsorptive periods in healthy humans. Am J Clin Nutr 66, $1151-1159$.

Alvarado M, Pacheco-Delahaye E, Schnell M \& Hevia P (1999) Dietary fiber in industrial tomato residue and its effects on glycaemic response and seric cholesterol in rats. Arch Latinoam Nutr 49, $138-142$.

Amend T \& Belitz HD (1991) Microstructural studies of gluten and a hypothesis on dough formation. Food Structure 10, 277-288.

Astrup A \& Raben A (1995) Carbohydrate and obesity. Int J Obes 19, S27-S37.

Bland JM \& Altman DG (1986) Statistical methods for assessing agreement between two methods of clinical measurement. Lancet i, $307-310$.

Bornet FRJ, Fontvieille AM, Rizkalla S, Colonna P, Blayo A, Mercier C \& Slama G (1989) Insulin and glycemic responses in healthy humans to native starches processed in different ways: correlation with in vitro alpha-amylase hydrolysis. Am J Clin Nutr 50, 315-323.

Brand JC, Colagiuri S, Crossman S, Allen A, Roberts DCK \& Truswell AS (1991) Low-glycemic index foods improve long-term glycemic control in NIDDM. Diabetes Care 14, 95-101.

Brand-Miller J, Foster-Powell K \& Colagiuri S (2003a) The New Glucose Revolution. New York: Marlowe and Company.

Brand-Miller JC, Hayne S, Petocz P \& Colagiuri S (2003b) Low-glycemic index diets in the management of diabetes. A meta-analysis of randomized controlled trials. Diabetes Care 26, 2261-2267.

Ebbeling CB, Leidig MM, Sinclair KB, Hangen J \& Ludwig DDS (2003) A reduced-glycemic load diet in the treatment of adolescent obesity. Arch Pediatr Adolesc Med 157, 773-779.

Federation of Bakers (2005) The British Bread and Bakery Snacks Market. Factsheet no. 3. Accessed 20 June 2006. http://www. bakersfederation.org.uk/publications/FS3 - UK Bakery Market.pdf.

Food and Agriculture Organization \& World Health Organization (1998) Carbohydrates in Human Nutrition. Report of a Joint FAO/WHO Expert Consultation. Rome: FAO.

Foster-Powell K, Holt SHA \& Brand-Miller JC (2002) International table of glycemic index and glycaemic load values: 2002. Am J Clin Nutr 76, 5-56.

Frost G, Leeds A, Trew G, Margara R \& Dornhorst A (1998) Insulin sensitivity in women at risk of coronary heart disease and the effect of a low glycemic diet. Metabolism 47, 1245-1251.

Granfeldt Y, Bjorck I \& Hagander B (1991) On the importance of processing conditions, product thickness and egg addition for the glycemic and hormonal responses to pasta: a comparison with bread made from pasta ingredients. Eur J Clin Nutr 45, 489-499.

Granfeldt Y, Eliasson AC \& Bjorck I (2000) An examination of the possibility of lowering the glycemic index of oat and barley flakes by minimal processing. J Nutr 130, 2207-2214.

Granfeldt Y, Wu CL \& Bjorck I (2006) Determination of glycaemic index; some methodological aspects related to the analysis of carbohydrate load and characteristics of the previous evening meal. Eur J Clin Nutr 60, 104-112.

Hallfrisch J \& Behall KM (2000) Mechanisms of the effects of grains on insulin and glucose responses. J Am Coll Nutr 19, 320S-325S.

Hayta M \& Alpaslan M (2001) Effects of processing on biochemical and rheological properties of wheat gluten proteins. Nahrung $\mathbf{5}$, 304-308.

Hoebler C, Karinthi A, Chiron H, Champ M \& Barry JL (1999) Bioavailability of starch in bread rich in amylose: metabolic responses in healthy subjects and starch structure. Eur J Clin Nutr 53, $360-366$.

Hoebler C, Karinthi A, Devaux MF, Guillon F, Gallant DJG, Bouchet B, Melegari C \& Barry JL (1998) Physical and chemical transformations of cereal food during oral digestion in human subjects. Br J Nutr 80, 429-436. 
Holt SHA, Brand-Miller JC \& Stitt PA (2001) The effects of equalenergy portions of different breads on blood glucose levels, feelings of fullness and subsequent food intake. J Am Diet Assoc 101, 767-773.

Holt SHA, Miller JCB, Petocz P \& Farmakalidis E (1995) A satiety index of common foods. Eur J Clin Nutr 49, 675-690.

Jenkins DJA, Wolever TMS, Jenkins AL, Giordano C, Giudici S, Thompson LU, Kalmusky J, Josse RG \& Wong GS (1986) Low glycemic response to traditionally processed wheat and rye products: bulgur and pumpernickel bread. Am J Clin Nutr 43, 516-520.

Jenkins DJA, Wolever TMS, Taylor RH, Barker $H$, Fielden $H$, Baldwin JM, Bowling AC, Newman HC, Jenkins AL \& Goff DV (1981) Glycemic index of foods: a physiological basis for carbohydrate exchange. Am J Clin Nutr 34, 362-366.

Langkilde AM, Champ M \& Andersson H (2002) Effects of highresistant-starch banana flour $(\operatorname{RS}(2))$ on in vitro fermentation and the small-bowel excretion of energy, nutrients, and sterols: an ileostomy study. Am J Clin Nutr 75, 104-111.

Liu S, Willett WC, Stampfer MJ, Hu FB, Franz M, Sampson L, Hennekens CH \& Manson JE (2000) A prospective study of dietary glycemic load, carbohydrate intake, and risk of coronary heart disease in US women. Am J Clin Nutr 71, 1455-1461.

Noakes M, Clifton PM, Nestel PJ, LeLeu R \& McIntosh G (1996) Effect of high-amylose starch and oat bran on metabolic variables and bowel function in subjects with hypertriglyceridemia. Am J Clin Nutr 64, 944-951.

Rashmi S \& Urooj A (2003) Effect of processing on nutritionally important starch fractions in rice varieties. Int J Food Science Nutr 54, 27-36.

Robertson MD, Currie JM, Morgan LM, Jewell DP \& Frayn KN (2003) Prior short-term consumption of resistant starch enhances postprandial insulin sensitivity in healthy subjects. Diabetologia 46, 659-665.

Velangi A, Fernandes G \& Wolever TMS (2005) Evaluation of a glucose meter for determining the glycemic responses of foods. Clin Chim Acta 356, 191-198.

Wolever TMS (1990) The glycemic index. World Rev Nutr Diet 62 , $120-185$.

Wolever TMS, Katzmanrelle L, Jenkins AL, Vuksan V, Josse RG \& Jenkins DJA (1994) Glycemic index of 102 complex carbohydrate foods in patients with diabetes. Nutr Res 14, 651-669.

Wolever TMS \& Mehling C (2002) High-carbohydrate-low-glycaemic index dietary advice improves glucose disposition index in subjects with impaired glucose tolerance. Br J Nutr 87, 477-487.

Wolever TMS \& Mehling C (2003) Long-term effect of varying the source or amount of dietary carbohydrate in postprandial plasma glucose, insulin, triacylglycerol, and free fatty acid concentrations in subjects with impaired glucose tolerance. Am J Clin Nutr 77, $612-621$. 